\title{
As Cortes Internacionais e a proteção das águas
}

DOSSIER ÁGUA E MULHER

\section{Fernanda Brusa Molino}

Advogada e Professora de Direito. Doutora e Mestra em Direito das Relações Econômicas Internacionais (PUC-SP). Mestra em Direito Empresarial (Universidad de Alcalá de Henares / Espanha). Especialista em Direito Penal (ESA-SP). Vinhedo [SP] Brasil <fbmlaw@gmail.com> https://orcid.org/0000-0001-5168-1852.

\section{Resumo}

Neste trabalho será apresentado o estudo das legislações internacionais que efetivam a proteção do meio ambiente e dos recursos hídricos para discorrer sobre a importância da proteção das águas no cenário internacional fazendo uso de relatórios e estudos científicos de entidades internacionais relacionadas às Nações Unidas, de modo a destacar a relevância da proteção das águas como direito humano e demonstrando sua presença em casos de Cortes Internacionais.

\section{Palavras-chave}

Proteção das Águas. Direito Internacional. Direitos Humanos.

\section{The International Courts and the protection of waters}

\begin{abstract}
This paper will present the study of the international laws that protect the environment and water resources to discuss the importance of water protection in the international scenario, using reports and scientific studies of international entities related to the United Nations, in order to highlight the relevance of the protection of waters as a human right and demonstrating their presence in cases of international courts.
\end{abstract}

\section{Keywords}

Protection of Water. International Law. Human Rights. 


\section{Introdução}

A água é um recurso extremamente importante para o ser humano e diversamente pouco valorizado em termos de proteção.

De modo geral os recursos naturais passaram a ser protegidos internacionalmente por intermédio de tratados e protocolos internacionais, ganhando relevância também no âmbito nacional. A partir desta proteção, são ampliadas as divergências econômicas e políticas com esta decisão, gerando consequências no cenário nacional e internacional que serão aqui apresentados como a disputa e reivindicações em cortes internacionais.

\section{2 . A proteção dos recursos naturais e da água no Direito Internacional}

Em 1972 ocorreu a Conferência das Nações Unidas sobre o Meio Ambiente Humano, também conhecido como Conferência de Estocolmo. Esta foi a primeira grande reunião de Estados organizada pela Organização das Nações Unidas (ONU) visando a discussão sobre questões relacionadas à degradação do meio ambiente e sua consequente proteção, realizada em junho na Suécia.

Assim, na Declaração da Conferência das Nações Unidas sobre o Meio Ambiente Humano, de 1972, há a previsão em seus princípios 1 e 2, de que:

1. O homem tem o direito fundamental à liberdade, à igualdade e ao desfrute de condições de vida adequadas em um meio ambiente de qualidade tal que lhe permita levar uma vida digna e gozar de bem-estar, tendo a solene obrigação de proteger e melhorar o meio ambiente para as gerações presentes e futuras. A este respeito, as políticas que promovem ou perpetuam o apartheid, a segregação racial, a discriminação, a opressão colonial e outras formas de opressão e de dominação estrangeira são condenadas e devem ser eliminadas.

2. Os recursos naturais da terra incluídos o ar, a água, a terra, a flora e a fauna e especialmente amostras representativas dos ecossistemas naturais devem ser preservadas em benefício das gerações presentes e futuras, mediante uma cuidadosa planificação ou ordenamento (ONU, 1992).

Deste modo, extrai-se princípios importantes para a proteção do meio ambiente, especialmente no cenário internacional, pronunciado o princípio da equidade intergeracional, da dignidade humana e a elevação do meio ambiente saudável a condição de direito humano, sendo considerado jus cogens.

Este documento internacional foi relevante, uma vez que contou com a participação de 113 países e mais de 400 organizações governamentais e não governamentais. Apesar de sua relevância, ficou evidente a polarização entre países desenvolvidos e não desenvolvidos com interesses distintos e sem estabelecimentos de metas mitigadoras e protetivas concretas, porém, foi o pontapé para a elaborações de novos documentos sobre o tema no âmbito global como no regional.

Após vinte anos da Conferência de Estocolmo em 1972, ocorreu a Conferência das Nações Unidas sobre o Ambiente e o Desenvolvimento, no Rio de Janeiro, em 1992. Este evento também ficou conhecido como Cúpula da Terra, Rio-92 e Eco-92.

Ele foi importante diante da necessidade de conciliação entre desenvolvimento socioeconômico e a proteção e conservação do meio ambiente e de seus recursos. Neste encontro, que contou com a presença de representantes de 172 países e variadas organizações ambientais, houve grandes avanços no campo jurídico relacionado à proteção do meio ambiente, pois foram elaborados cinco importantes acordos ambientais sendo eles: a Declaração do Rio sobre Meio Ambiente e Desenvolvimento, a Agenda 21, os Princípios para a Administração Sustentável das Florestas; a Convenção da Biodiversidade; e a Convenção do Clima.

Assim, na Declaração do Rio sobre Meio Ambiente e Desenvolvimento estão previstos os princípios abaixo elencados: 
2. Os Estados, de acordo com a Carta das Nações Unidas e com os princípios do direito internacional, têm o direito soberano de explorar seus próprios recursos segundo suas próprias políticas de meio ambiente e de desenvolvimento, e a responsabilidade de assegurar que atividades sob sua jurisdição ou seu controle não causem danos ao meio ambiente de outros Estados ou de áreas além dos limites da jurisdição nacional.

23. O meio ambiente e os recursos naturais dos povos submetidos a opressão, dominação e ocupação serão protegidos.

25. A paz, o desenvolvimento e a proteção ambiental são interdependentes e indivisíveis (ONU, 1992).

Isto posto, é evidente a coordenação de esforços em reiterar a proteção do meio ambiente e de recursos naturais, devendo observar todas as normas e responsabilidades para a exploração dos mesmos de modo a controlar possíveis danos, sendo impossível segregar a proteção do meio ambiente com o desenvolvimento, fomentando a ideia do desenvolvimento sustentável, que vem a lume com o Relatório Brundtland.

Com base ainda na Declaração do Rio sobre Meio Ambiente e Desenvolvimento é perceptível em relação ao desenvolvimento econômico e de promoção do meio ambiente ante a comunidade internacional, sendo evidente nos princípios 12 e 18:

12. Os Estados devem cooperar na promoção de um sistema econômico internacional aberto e favorável, propício ao crescimento econômico e ao desenvolvimento sustentável em todos os países, de forma a possibilitar o tratamento mais adequado dos problemas da degradação ambiental. As medidas de política comercial para fins ambientais não devem constituir um meio de discriminação arbitrária ou injustificável, ou uma restrição disfarçada ao comércio internacional. Devem ser evitadas ações unilaterais para o tratamento dos desafios internacionais fora da jurisdição do país importador. As medidas internacionais relativas a problemas ambientais transfronteiriços ou globais deve, na medida do possível, basear-se no consenso internacional.

18. Os Estados notificarão imediatamente outros Estados acerca de desastres naturais ou outras situações de emergência que possam vir a provocar súbitos efeitos prejudiciais sobre o meio ambiente destes últimos. Todos os esforços serão envidados pela comunidade internacional para ajudar os Estados afetados (ONU, 1992).

Tais previsões levam à reflexão de que ocorriam problemas entre os países quando o tema era o desenvolvimento econômico e o uso de recursos naturais e que tais demandas poderiam ser ampliadas, ocorrendo à previsão expressa de que fosse propício o crescimento econômico em todos os países permitindo o tratamento igualitário quanto aos danos ambientais, sem imposição de ações discriminatórios ou restritivas, especialmente no comercio internacional.

Ademais, fica destacado a necessidade de cooperação internacional em caso de desastres naturais e situações emergenciais que possa prejudicar o meio ambiente de outros países envolvidos, observando aqui o atendimento ao princípio da cooperação internacional no que tange o direito internacional, princípio este amplamente utilizado em acordos e tratados internacionais de vigência global.

Com base na Agenda 21, também redigida na Conferência das Nações Unidas sobre Meio Ambiente e Desenvolvimento é destacado a importância na proteção dos recursos naturais coordenando com ações econômicas sustentáveis, materializando ações concretas em diversos aspectos econômicos e ambientais, destacando a colaboração entre a sociedade em geral envolvendo os países e instituições internacionais, organizações não governamentais, populações indígenas, mulheres, trabalhadores, sindicatos, comércio, indústrias e agricultura.

Especificamente sobre a água, a Agenda 21 estabelece uma série de ações relacionadas à política de Manejo de Ecossistemas frágeis como os desertos e locais que sofrem com a seca, provendo ações mitigadoras contra a desertificação e efeitos da seca. Ainda se destaca o capítulo sobre Proteção da qualidade e do abastecimento dos recursos hídricos, sendo que a Organização das Nações Unidas informa: 
18.1 Os recursos de água doce constituem um componente essencial da hidrosfera da Terra e parte indispensável de todos os ecossistemas terrestres. $O$ meio de água doce caracterizase pelo ciclo hidrológico, que inclui enchentes e secas, cujas consequências se tornaram mais extremas e dramáticas em algumas regiões. [...]

18.2 A água é necessária em todos os aspectos da vida. O objetivo geral é assegurar que se mantenha uma oferta adequada de água de boa qualidade para toda a população do planeta, ao mesmo tempo em que se preserve as funções hidrológicas, biológicas e químicas dos ecossistemas, adaptando as atividades humanas aos limites da capacidade da natureza e combatendo vetores de moléstias relacionadas com a água (ONU,1992).

Torna-se evidente a necessidade da proteção dos recursos hídricos diante de sua indispensabilidade para a vida humana e para os ecossistemas terrestres, ademais, é notificado que não basta a oferta adequada, mas também deve-se prezar pela oferta de água que atenda à padrões mínimos de boa qualidade para a população e o planeta em geral.

De fato, fica claro a necessidade de proteção dos recursos naturais de modo geral, mas especificamente da água, sendo para isto utilizado outros diplomas legais internacionais sobre o tema.

A Convenção sobre a Proteção e a Utilização dos Cursos de Água Transfronteiriços e dos Lagos Internacionais, firmado em 1992, em Helsinque, no âmbito da Comissão Econômica das Nações Unidas para a Europa (UNECE, 1947) estabelece como medidas a serem adotadas por todos em seu artigo $2^{2}$ :

1 - As Partes devem tomar todas as medidas apropriadas para prevenir, controlar e reduzir todo e qualquer impacte transfronteiriço.

2 - As Partes, em particular, devem tomar todas as medidas apropriadas:

a) Para prevenir, controlar e reduzir a poluição das águas que possam vir a ter um impacte transfronteiriço;

b) Para assegurar que as águas transfronteiriças sejam utilizadas de forma a garantir uma gestão da água racional e ecologicamente adequada, a conservação dos recursos hídricos e a proteção ambiental;

c) Para assegurar que se faça um uso razoável e equitativo das águas transfronteiriças, tendo particularmente em conta o seu carácter transfronteiriço, no caso de actividades que causem ou possam vir a causar um impacte transfronteiriço;

d) Para assegurar a conservação e, caso seja necessário, a recuperação dos ecossistemas.

3 - As medidas de prevenção, de controlo e de redução da poluição da água devem ser tomadas, sempre que possível, na fonte.

4 - Estas medidas não devem resultar, directa ou indirectamente, de nenhum transfer de poluição para outros lugares (UNECE, 1992).

Portanto, esta convenção de aplicabilidade regional, assegura a proteção dos recursos hídricos de modo específico, contudo coordenando as mesmas premissas estabelecidas nas Declarações supramencionadas de âmbito global, merecendo destaque a necessidade de recuperação dos ecossistemas afetados quando necessário.

Outro ponto de destaque é que ocorra o uso razoável e equitativo das águas transfronteiriças, uma vez que a previsão tem total correlação com a cooperação internacional e a manutenção da paz em territórios vizinhos, observando a soberania de cada Estado de modo relativizado de modo a atender aos direitos mínimos de cada população.

Ainda no mesmo dispositivo legal da Convenção sobre a Proteção e a Utilização dos Cursos de Água Transfronteiriços e dos Lagos Internacionais são expressos os princípios que o regem:

5 - A quando da adopção das medidas indicadas nos parágrafos 1 e 2 do presente artigo, as Partes devem guiar-se pelos seguintes princípios:

a) O princípio da precaução, em virtude do qual elas não diferem a elaboração de medidas destinadas a evitar que o lançamento de substâncias perigosas possa ter um impacte transfronteiriço cujo motivo a pesquisa científica não demonstrou ple- 
namente o elo de causalidade entre essas substâncias, por um lado, e um eventual impacto transfronteiriço, por outro;

b) 0 princípio do poluidor-pagador, em virtude do qual os custos das medidas de prevenção, controlo e redução devem ser suportados pelo poluidor;

c) Os recursos hídricos devem ser geridos de molde a responder às necessidades da geração actual sem comprometer a capacidade de as gerações futuras satisfazerem as suas próprias necessidade (UNECE, 1992).

Os princípios da precaução, do poluidor-pagador e da equidade intergeracional mais uma vez são refletidos em um documento internacional relacionado ao meio ambiente.

Este documento ainda prevê a cooperação bilateral e multinacional em termos de troca de informação, monitoramento e vigilância como também a assistência mutua em caso de risco ou situação crítica transfronteiriça, destacando a importância e relevância relacionada à proteção dos recursos hídricos e em casos de proteção de águas transfronteiriças, sendo necessário o trabalho conjunto e colaborativo ultrapassando o caráter soberano em prol do meio ambiente.

Importante ressaltar que esta Convenção possui dois protocolos, sendo o primeiro relacionado à melhora na qualidade da água de modo a promover o bem-estar e a saúde, firmado em 1999 e o segundo, firmado em 2003, relativo à responsabilidade civil e responsabilidade por danos causados pelos efeitos transfronteiriços correlatos às atividades industriais.

Ainda no plano internacional, mas agora de aplicação global, encontra-se a Convenção sobre o Direito Relativo à Utilização dos Cursos de Água para fins Diversos dos de Navegação, firmado em 1997, sendo este um dos pilares na proteção do Direito Internacional das Águas. Para a elaboração deste documento houve a participação de três entidades civis sendo elas a Associação de Direito Internacional (ILA), de origem norte americana; o Instituto de Direito Internacional (IDI), com origem suíça; e a Associação Internacional de Direito das Águas (AIDA), de origem italiana.

A Convenção sobre o Direito Relativo à Utilização dos Cursos de Água para fins Diversos dos de Navegação contam com nuances e normas advindas de diversos diplomas relacionados à proteção das aguas existentes no mundo, permitindo observar regras das Normas de Kelsinki com relação às aguas superficiais; Normas de Montreal no tocante à poluição; Norma de Seul sobre águas subterrâneas; Resolução de Madrid em relação aos cursos d'agua para uso diferente da navegação; Resolução de Salzburgo versando sobre o direito dos Estados no uso das aguas internacionais; Resolução de Atenas sobrea poluição de rios e lagos e o Modelo de Acordo de Bellagio quando versa sobre o Modelo de Acordo sobre aquíferos transfronteiriços (Lane, 2015).

Portanto, este diploma legal é um compilado da utilização de diversos textos legais correlatos às águas aplicáveis pelo mundo, objetivando trazer maior proteção internacional contando com a colaboração de especialista sobre o tema.

Em suma, a apresentação dos textos legais supramencionados evidencia a importância do tema e necessidade de proteção internacional para os recursos naturais, especialmente a água, elencando-o como direito fundamental componente do rol de direitos humanos, revestindo do status de jus cogens.

\section{Os recursos hídricos no planeta e a urgência em sua proteção}

No Relatório Mundial das Nações Unidas sobre Desenvolvimento dos Recursos Hídricos de 2018 é apresentado uma série de informações relevantes que demonstram a necessidade urgente de proteção dos recursos hídricos no planeta, com diversos estudos que demonstram a fragilidade e risco na oferta deste recurso natural em razão do uso irracional. A demanda de água é calculada em torno de $4600 \mathrm{~km}^{3}$ /ano nos dias de hoje, segundo o Relatório Soluções baseadas na Natureza para a Gestão da Água. Estima-se ainda que este número aumen-te entre $20 \%$ ou $30 \%$ até 2050 (ONU, 2018). A água já é um problema em muitos lugares do planeta diante da escassez hídrica especialmente das águas superficiais conforme se verifica na Figura 1. 


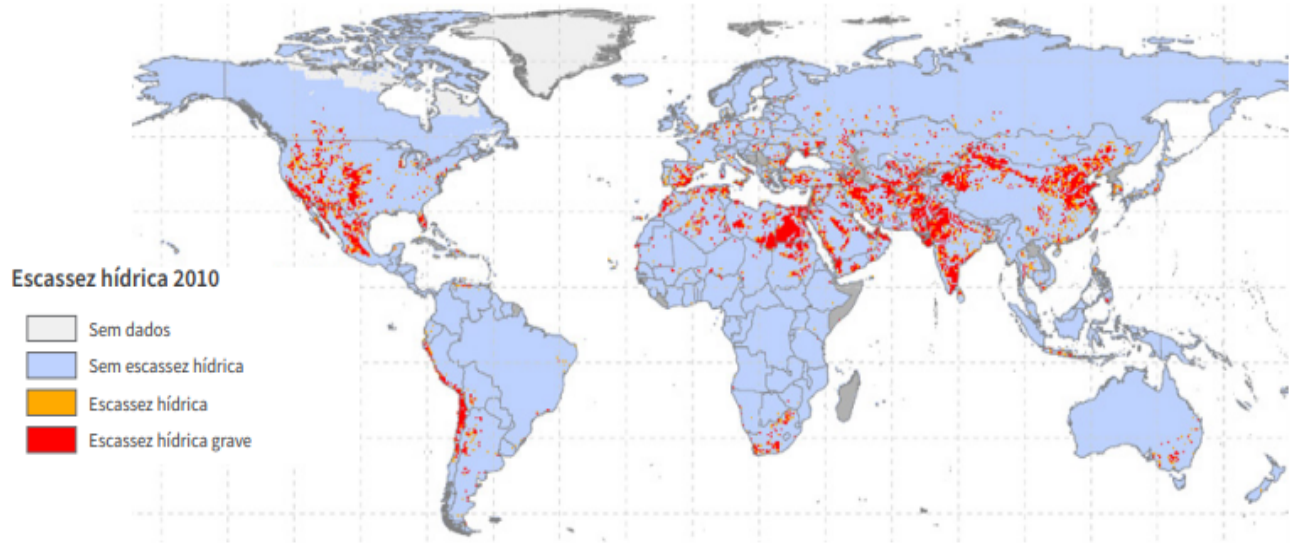

Figura 1. Escassez hídrica 2010. Fonte: Burek et al. (2016, fig. 4-39, p. 65).

Para a região ser considerada escassa em recursos hídricos é necessário que o total de captação hídrica para o uso humano no ano compreenda de $20 \%$ a $40 \%$ do total disponível de recursos hídricos superficiais renováveis, e no caso das áreas gravemente escassas em água, estas compreendem locais em que o total de captação hídrica para o uso humano ultrapasse $40 \%$ do total disponível em águas superficiais renováveis no ano (Burek, 2016).

Foi realizado ainda um estudo com projeções para 2050 por iniciativa do Water Futures and Solutions Initiative (WFaS), que é um projeto de água global colaborativo entre setores para oferecer uma avaliação sobre a situação global da água no presente e no futuro. Para isto o WFaS desenvolveu um conjunto de cenários de futuros globais de água, que foram quantificados e avaliados com uma abordagem multi-modelo. Estes cenários futuros relevantes para a água foram baseados no uso da água narradas que ampliam os Percursos Socioeconômicos Compartilhados (SSPs) e a Concentração Representativa Caminhos (RCPs); estes compreendem um conjunto de caminhos desenvolvidos por uma grande comunidade global ao longo de vários anos para as avaliações do Painel Intergovernamental sobre as Alterações Climáticas (IPCC) (Burek, 2016).

Assim, o cenário intermediário apresentado na Figura 2 considera que o desenvolvimento do planeta ocorra com tendências apresentadas no passado em relação aos cenários econômico, tecnológico e social, não apresentando grandes divergências dos padrões históricos já apresentados.

Portanto, verifica-se que a tendência é que haja a escassez hídrica grave em grande parte das regiões, especialmente nos continentes africano, europeu, oriente médio e asiático até 2050.

Um ponto de atenção é que o cenário projetado anuncia uma piora em grande parte do planeta, contudo, existem regiões onde se projeta uma melhora no cenário e oferta de recursos hídricos como no caso da América do Norte, Europa Ocidental e alguns países africanos, evidenciando que algumas ações já estabelecidas poderão auxiliar e reverter a situação em muitos grupos populacionais.

Considerando ainda as projeções supramencionadas, na Figura 3 foram analisadas a quantidade de águas disponíveis e sua demanda considerando os marcos de 2010 e 2050 . A análise considerou a disponibilidade de água superficial e a sua demanda sendo mensurada $\mathrm{em}^{\mathrm{km}} /$ ano e considerando os anos de 2010 e 2050. Deve-se lembrar que a projeção considera o cenário intermediário (SSP2 e RCP6.0), não sendo o cenário mais grave e prejudicial estudado.

Considerando os números apresentados em 2010, verifica-se que a demanda de água global compreende aproximadamente 8,6\% se comparado com a oferta total. A grande parte da demanda está destinada à Ásia, concentrando 66\%, seguida pela América do Norte e Central, com 14\% e Europa, com 10\%.

Considerando o cenário intermediário, projeta-se que a demanda de água represente aproximadamente $11 \%$ da oferta total de águas superficiais para 2050. Nesta projeção constata-se que haverá grande crescimento da demanda para o continente asiático, que representará $86 \%$ da demanda total, seguido do continente africano que aumentou sua demanda de 5\% em 2010 para 8\% em 2050. 


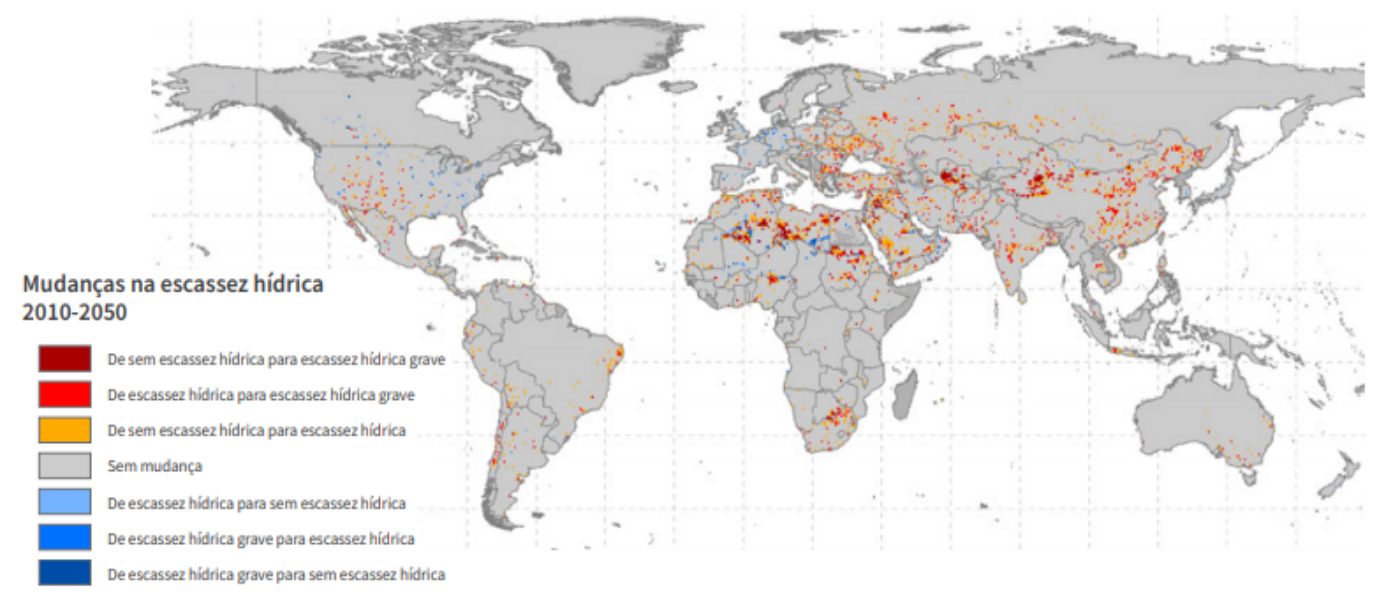

Figura 2. Mudança projetada da escassez hídrica* até 2050 com base no cenário intermediário SSP2 - RCP 6.0 Fonte: Burek et al. (2016, fig. 4-39, p. 65).

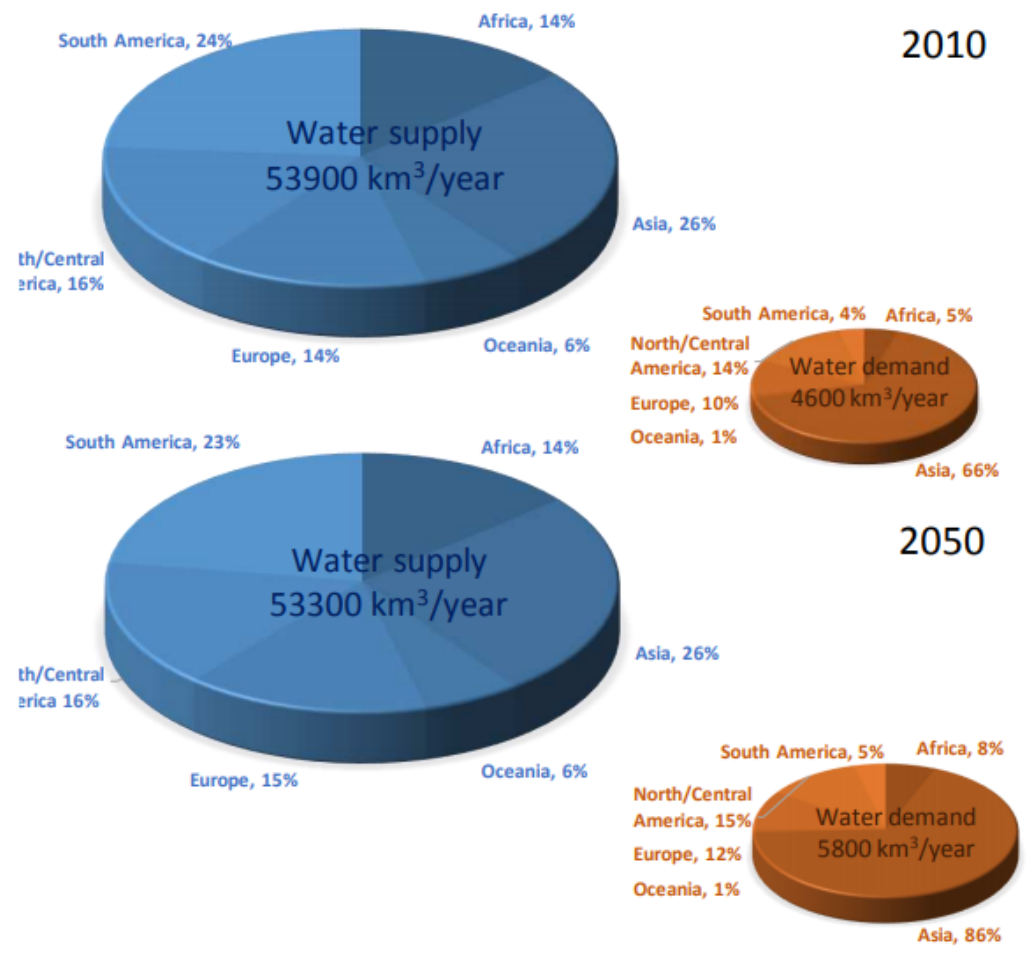

Figura 3. Demanda de Água 2010. Fonte: Burek et al. (2016, fig. 4-34, p. 58).

Esta análise apresenta preocupações, uma vez que se vislumbra que terá grande tensão social e econômico no continente asiático ante a diminuição da demanda total de águas superficiais e subterrâneas aliado com o grande crescimento populacional e econômico na região, permitindo que ocorram grandes disputas territoriais e de controle político no mundo.

Isto já aparece nas tensões entre as Coreias, que aparentemente estão articulando ações políticas para selar a paz, contudo, ficam dúvidas quanto a este e outras tensões políticas na região como a China, Mianmar, Nepal e os países do Oriente Médio, como Síria, Afeganistão, Israel, Palestina.

Recorrendo ainda ao Painel Intergovernamental para mudança do clima (IPCC), a escassez de recursos hídricos é outro fenômeno muito analisado quando se estuda os efeitos da Mudança no Clima, sendo umas das consequências diretas da alta emissão de gases causadores do efeito estufa. Assim, o Painel realiza publicações periódicas sobre seus estudos desde a década de 90, sendo que o último relatório publicado pelo Painel ocorreu em 2014. 
O quinto relatório do Painel Intergovernamental para Mudança do Clima de 2014 apresenta dados desanimadores relacionados aos recursos hídricos, uma vez que serão diretamente impactados com os efeitos oriundos da mudança do clima ocasionados pelo excesso de emissão de gases causadores de efeito estufa, onde verifica-se notadamente o aumento gradual de temperatura climática, como também nos oceanos, ocasionando o aumento dos níveis dos oceanos e o derretimento de geleiras e glaciares.

Com base no quadro infra apresentado (Figura 4), claramente é percebido que todas as regiões do planeta sofrerão efeitos negativos em relação a oferta de recursos hídricos com exceção dos Pequenos Estados Insulares e regiões polares (Ártico e Antártico).

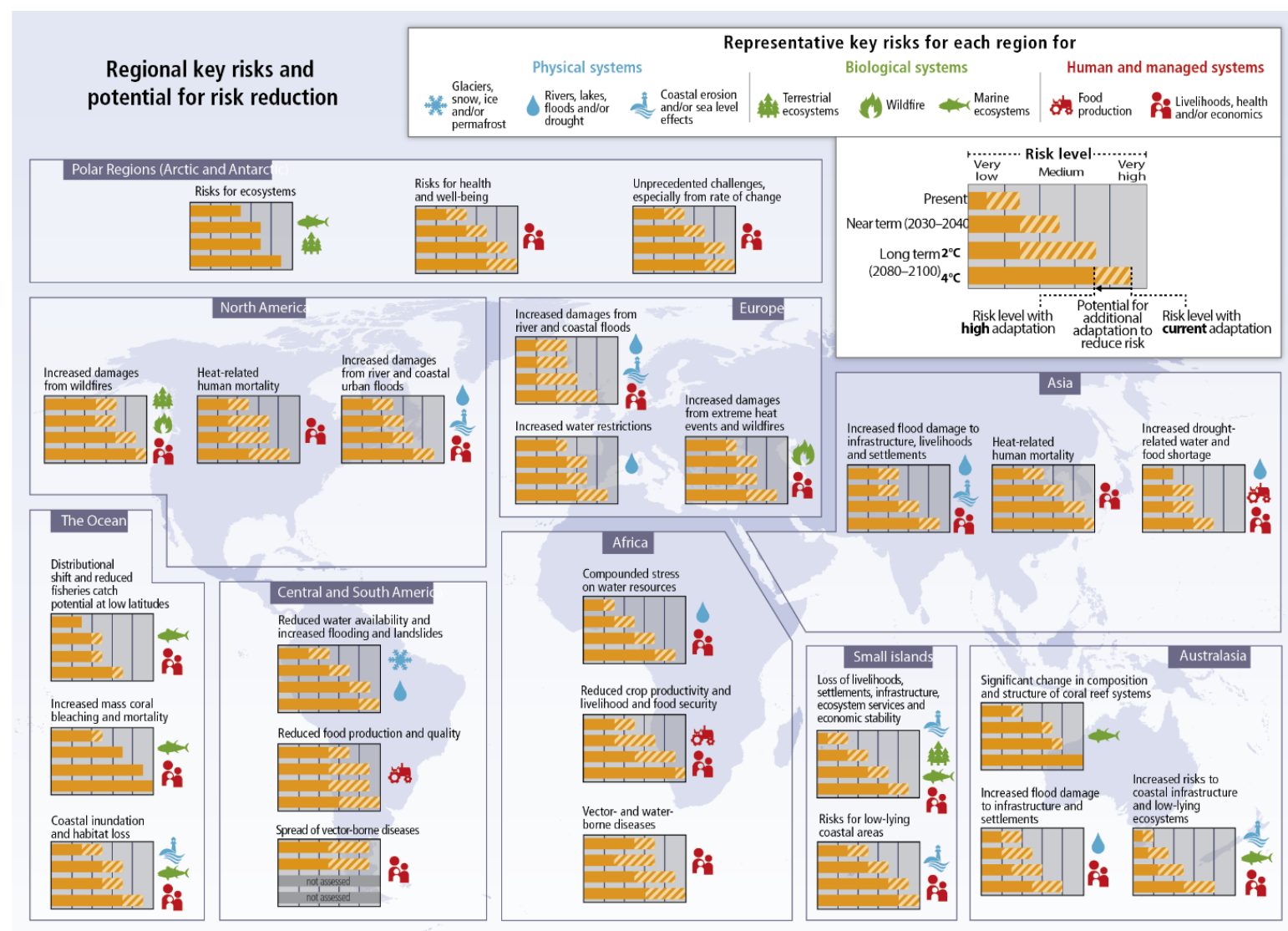

Figura 4. Riscos-chave representativos para cada região do planeta. Fonte: ONU. Programa das Nações Unidas para o Meio Ambiente e Organização Meteorológica Mundial. Painel Intergovernamental para mudança do clima (IPCC) (Climate Change, 2015).

Sucintamente, os grande pontos de atenção são registrados na Europa com risco mediano de aumento das restrições em relação ao uso das aguas em 2030 a 2040; na América Latina tem-se a projeção de que ocorrerá a redução dos níveis de agua disponíveis com risco mediano para 2030; na África ocorrerá um risco mediano entre 2030 e 2040 quanto ao agravamento no estresse dos recursos hídricos; e na Ásia com aumento da escassez de agua e da produção de alimentos representando um nível médio de risco em 2030 a 2040.

Diante de todo o exposto, os recursos naturais em especial os recursos hídricos estão sendo afetados pela ação do homem em razão das mudanças do clima e uso irracional, sendo este cenário agravado com o passar dos anos nos diversos continentes.

A reserva de água que existe no planeta está sendo alvo de constantes ações desproporcionais perpetradas pelas diversas esferas da sociedade, revelando também sua proteção ante a previsão de diminuição dos níveis e marcos de água hoje disponíveis, envolvendo as águas superficiais e subterrâneas. 
Com a afetação no nível de suprimento e reserva de águas disponíveis, vislumbram-se efeitos negativos e concatenados que serão refletidos em diversos habitats e biomas, atingindo diretamente os homens.

Com isto, constata-se que o ser humano e sua sobrevivência serão colocadas em xeque, diante da relevância dos recursos hídricos para o homem, verificando que produtividade e abastecimento em determinadas regiões serão gravemente afetadas a depender das ações que serão tomadas para a proteção e mitigação de efeitos junto ao meio ambiente e os recursos naturais de modo geral.

\section{A jurisprudência nas Cortes Internacionais}

Com este cenário atual e as previsões apresentadas muitas instituições e pessoas acabam demandando judicialmente em cortes nacionais e internacionais, buscando a proteção do uso indiscriminado e irracional das águas.

Sucintamente será apresentada uma seleção de jurisprudências relacionadas às principais cortes internacionais como a Corte Interamericana de Direitos Humanos e a Corte Internacional de Justiça, a primeira com atuação jurisdicional regional e a segunda, com jurisdição global.

\subsection{Corte Interamericana de Direitos Humanos (IDH)}

Em 2005 ocorreu o julgamento do caso Comunidad Indígena Sawhoyamaxa del Pueblo Enxet Lengua y sus Miembros contra o Paraguai. Neste caso, a comunidade indígena argumentava sobre a violação de normas apresentadas na Convenção Americana sobre Direitos Humanos pelo Paraguai envolvendo o direito a vida (artigo $4^{\circ}$ ), da integridade pessoal (artigo $5^{\circ}$ ), da propriedade privada (artigo 8을 ) e proteção judicial (artigo 25) em conexão com a obrigação de respeito aos direitos (artigo 1.1) e com o dever de adoção de disposições de direito interno (artigo 2) por não garantir o direito de proteção ancestral da Comunidade Indígena que estava em tramitação desde 1991.

A Corte neste julgamento reconheceu o direito de acesso à água potável estando este direito intrinsecamente ligado ao direito à saúde, presente no Protocolo de São Salvador. Este posicionamento está expresso no julgado:

Es un hecho no controvertido por el Estado que, 31 miembros de la Comunidad, la mayoría niños y niñas, han fallecido, entre 1991 y 2003. De las 31 muertes referidas, 9 corresponden a mayores de 18 años, 20 a niños y niñas y 2 no tienen datos sobre la edad de la persona al momento de fallecer. Las causas de muertes de los 20 casos de niños y niñas son tétanos, sarampión, enterocolitis, pulmonía, deshidratación, caquexia y neumonía, enfermedades que pudieron prevenirse y curarse, o mejor aún impedirse, permitiendo a la comunidad que vida en un medio ambiente saludable, sin estar expuesta a los riesgos de su situación indefinida a la orilla de una carretera pública.

159. En tal sentido, está acreditado que las condiciones de vida que actualmente debe soportar la Comunidad Sawhoyamaxa son infrahumanas.

160. Las muertes de miembros de la Comunidad, en la mayoría niños, en la generalidad de los casos pudieron haberse evitado con una adecuada alimentación, salubridad y asistencia médica. Si el Estado hubiese garantizado a la Comunidad Sawhoyamaxa su derecho a vivir en su territorio ancestral o hábitat tradicional y así poder ejercer sus actividades tradicionales de subsistencia, las condiciones de vida de sus miembros hubieran mejorado.

161. La precaria situación de los miembros de la Comunidad, provocada, según lo expresado por el propio Estado en el decreto de emergencia № 3789 por la privación del acceso a sus medios de subsistencia tradicionales ligados a su identidad cultural, se constata además porque no tienen acceso a agua potable, servicios sanitarios y a materiales para construir o reparar sus casas o leña para cocinar. No pueden proveerse de madera para la construcción de las casas y leña para cocinar porque si bien su propio hábitat los circunda, el acceso les está prohibido.

$[\ldots]$ 
219. Asimismo, la Comisión pretende que dentro de las medidas de reparación se incluya la protección de las tierras reclamadas por la Comunidad con el fin de asegurar que al territorio reclamado no se le extraigan sus recursos naturales, en especial sus bosques, y se afecte en definitiva la práctica de sus actividades tradicionales de subsistencia. Finalmente, la Comisión solicita que el Estado de Paraguay adopte normas de derecho interno que garanticen los derechos reconocidos en la legislación paraguaya a favor de los pueblos indígenas.

[...]

2. Habilitar el área reclamada por la Comunidad Indígena Sawhoyamaxa y sus miembros con servicios básicos, incluyendo agua potable e infraestructura sanitaria, un centro de salud y un establecimiento escolar. (Comissão Interamericana de Direitos Humanos, 2005).

Por fim, o Paraguai foi condenado por violação de todos os artigos expressos sendo necessário adotar medidas de reparação e de salvaguarda de todos os direitos fundamentais violados.

Este julgado foi relevante, tendo como precursor o caso Comunidad Indigena Xákmok Kásek contra Paraguai, após isto muitos outros que se seguiram, o que demonstrou a vocação da Corte Interamericana na proteção ao acesso à água e que esta estivesse sua oferta atrelada à qualidade, correlacionando a proteção ao meio ambiente e à saúde, direitos presentes no rol dos tratados sobre direitos humanos como no caso Comunidad Indígena Xákmok Kásek del Pueblo Enxet Lengua y sus Miembros contra o Paraguai (Comissão Interamericana de Direitos Humanos, 2009), julgado em 2009, onde houve maior destaque a proteção da agua:

190. The Commission notes further that the lack of land is not the only problem besetting the Xákmok Kásek community. It is also plagued by unemployment, illiteracy, a high incidence of preventable diseases, malnutrition, dwellings unfit for human inhabitance, limited access to and use of health services and drinking water, and marginalization caused by economic, geographic and cultural factors.

$[\ldots]$

274. Furthermore, as has been shown throughout this application, the Indigenous Community does not have even the most basic health, food and education services. The Commission therefore believes it is vital that the State immediately provides the members of the Xákmok Kásek Indigenous Community with adequate goods, water, education, health services, and access to the food necessary for their subsistence.

$[\ldots]$

291. As a consequence, the Commission is asking the Honorable Court to order the State:

$[\ldots]$

d. Immediately provide the members of the Xákmok Kásek Indigenous Community with adequate goods and services, relating to water, education and health care services, and access to the food necessary for their subsistence. ${ }^{1}$

\footnotetext{
1 190. A Comissão observa ainda que a falta de terra não é o único problema que afeta a comunidade Xákmok Kásek. Também sofre com desemprego, analfabetismo, alta incidência de doenças evitáveis, desnutrição, moradias impróprias para o habitar humano, acesso limitado e uso de serviços de saúde e água potável e marginalização causada por fatores econômicos, geográficos e culturais.

$[\ldots]$

274. Além disso, como foi demonstrado ao longo desta solicitação, a Comunidade Indígena não possui nem mesmo os serviços básicos de saúde, alimentação e educação. Portanto, a Comissão considera vital que o Estado ofereça imediatamente aos membros da Comunidade Indígena Xákmok Kásek bens adequados, água, educação, serviços de saúde e acesso aos alimentos necessários à sua subsistência.

[...]

291. Por conseguinte, a Comissão pede ao Tribunal que ordene ao Estado:

[...]

d. Imediatamente fornecer aos membros da Comunidade Indígena Xákmok Kásek bens e serviços adequados, relacionados à água, educação e serviços de saúde, e acesso aos alimentos necessários para sua subsistência.

[Tradução livre].
} 
Importante destacar a Medida Provisória 382/10 - Comunidades Indígenas de la Cuenca del Río Xingu, Pará, Brasil, onde a Comissão Interamericana de Direitos Humanos outorgou medidas cautelares em favor das comunidades indígenas da bacia do Rio Xingu no Pará com a suspensão das obras de Belo Monte até que as medidas de proteção da vida, saúde e integridade pessoal dos membros das comunidades indígenas fossem executadas. Apesar da atuação da Comissão, o Brasil se pautou em sua soberania e recusou suspender as obras da usina, e diante da situação a Comissão Interamericana de Direitos Humanos acabou revogando a medida cautelar.

Assim, destaca-se mais uma vez a salvaguarda do acesso à água potável como direito básico para a subsistência e garantia de vida na Corte Interamericana de Direitos Humanos.

\subsection{Corte Internacional de Justiça (ICJ)}

A Corte Internacional de Justiça, instância máxima jurisdicional no âmbito nas Nações Unidas, realiza julgamentos em casos que versem sobre assuntos especialmente previstos na Carta das Nações Unidas ou em tratados e convenções em vigor.

Assim, desde 1946 realizou a análise e julgamento de temas pertinentes aos tratados das Nações Unidas, inclusive sobre a água.

O caso mais emblemático foi o Projeto Gabcíkovo-Nagymaros (Hungria v. Eslováquia), onde Hungria e Eslováquia notificaram em conjunto a Corte Internacional de Justiça, em 1993, sobre divergências relacionadas à execução do Tratado de Budapeste de 1977 que consistia na construção e exploração de um sistema de barragem denominado Gabcíkovo-Nagymaros.

Neste projeto a Hungria suspendeu o projeto e depois o abandonou sob a alegação de que o mesmo traria graves riscos ao meio ambiente na Hungria e prejudicaria o abastecimento de água em Budapeste. Entretanto, a Eslováquia insistiu no cumprimento das obrigações estabelecidas no tratado e, posteriormente, planejou um projeto alternativo sendo implantado apenas na Eslováquia, acarretando efeitos para a Hungria em relação ao acesso à água.

Em 15 de setembro de 1997, a Corte Internacional de Justiça proferiu sentença em que reconhecia a violação de obrigação por ambas às partes, sendo solicitado que os Estados fizessem uso de meios diplomáticos para a realização dos objetivos do Tratado de Budapeste. Assim, a Comunidade Europeia realizou a avaliação do impacto ambiental na região e financiou outro programa para auxiliar a Eslováquia em relação à sua política de energia. (Corte Internacional de Justiça, 1998).

Assim, em 1998, A Eslováquia apresentou pedido de julgamento adicional alegando que a Hungria não aplicou voluntariamente o acórdão de 25 de setembro de 1997. Em 21 de julho de 2017, a Corte Internacional de Justiça comunicou a ambos os Estados sua decisão de declarar encerrada a tramitação processual de julgamento adicional por intermédio do pedido da Eslováquia em junho sobre a desistência sobre o processo adicional, sendo acatado pela Hungria. (Corte Internacional de Justiça, 1998).

Outra referência é o caso Moinhos de Celulose no rio Uruguai (Argentina versus Uruguai), sendo peticionado em 2006 pela Argentina que alegava que as usinas representavam ameaça para o rio e o meio ambiente e poderiam prejudicar a qualidade das águas do rio, e gerariam potenciais danos transfronteiriços à Argentina, uma vez que o Uruguai aprovou unilateralmente a construção destes conjuntos, contrariando o Estatuto do Rio Uruguai.

A decisão da Corte Internacional de Justiça sinalizou que o Uruguai falhou com a obrigação de notificação de empreendimentos nas margens do Rio Uruguai conforme estabelecia o Tratado do Rio Uruguai, contudo nas demais alegações a Argentina não tinha razão e, por fim, a Corte argumentou que as partes deveriam continuar cooperando na gestão conjunto do recurso hídrico em questão (Corte Internacional de Justiça, 2006).

A Corte possui outras demandas relacionadas à proteção das águas, mas acabam sendo versadas indiretamente e correlacionadas com o direito ao meio ambiente saudável e o direito à vida, 
diferentemente dos casos anteriormente apresentando que buscaram a proteção efetiva das águas e sua qualidade.

Importante destacar que as jurisprudências apresentadas demonstram grande avanço e uma mudança de contexto, ampliando os meios de proteção do meio ambiente saudável de modo genérico para uma proteção mais direcionada e eficiente, correlacionando expressamente outros recursos naturais como o clima, os mares, as águas, o solo entre outros.

\section{Conclusões}

Diante deste estudo, fica demonstrado que os recursos hídricos de modo geral estão sendo afetados por conta do uso irracional e descontrolado, aliado as outras ações, sendo apresentado dados científicos utilizados pelos organismos internacionais destinados às pesquisas e componentes das Nações Unidas.

Isto evidencia a imparcialidade e responsabilidade na publicidade destas informações, evidenciando a necessidade de ações mais efetivas para a proteção das águas de modo geral ante as projeções idealizadas e mostram a grande possibilidade de escassez gradativa deste recurso tão importante para a sobrevivência do homem e outras espécies.

Com isto é apresentado a mudança de comportamento também no plano jurisdicional internacional e de documentos legais de aplicação internacional, evidenciando a mudança de um paradigma.

Isto porque foram e estão sendo pleiteadas proteção efetiva em relação aos recursos hídricos, seu acesso e sua qualidade. Ante toda a explanação realizada verificou-se a destinação de pleitos tanto no âmbito regional, especialmente no americano com a apresentação de casos apresentados à Corte Interamericana de Direitos Humanos e à Comissão Interamericana de Direitos Humanos, como também da Corte Internacional de Justiça, órgão jurisdicional no âmbito das Nações Unidas.

Diante dos casos apresentados, é latente a mudança de entendimento dos tribunais internacionais buscando oferecer proteções mais efetivas e menos genéricas, que de fato possam ser implementadas, apesar de alguns não atendimentos às decisões proferidas por parte de Estados, especialmente nos casos americanos.

Esta mudança também é perceptível por parte da sociedade que clama também junto aos tribunais nacionais pela proteção das águas e a aplicabilidade eficaz das legislações existentes, buscando articular a uma mudança de comportamento da sociedade de modo que a preservação dos recursos hídricos independa de legislações e decisões judiciais.

\section{Referências}

Amorim, J. A. A. (2015). A ONU e o meio ambiente: direitos humanos, mudanças climáticas e segurança internacional no século XXI. São Paulo: Atlas.

Antunes, P. de B. (2016). Direito ambiental. 18. ed. São Paulo: Atlas.

Burek, P. et. al. (2016). Water Futures and Solution: Fast Track Initiative (Final Report). IIASA Working Paper. Laxenburg, Austria, International Institute for Applied Systems Analysis (IIASA), 2016. Recuperado de: < http://pure.iiasa.ac.at/id/eprint/13008/1/WP-16-006.pdf>.

Comissão Interamericana de Direitos Humanos (2005). Caso 12.419, Comunidad Indígena Sawhoyamaxa del Pueblo Enxet-Lengua y sus Miembros v. Paraguai. Recuperado de: < http://www.cidh.oas.org/ demandas $/ 12.419 \% 20$ Sawhoyamaxa\%20Paraguay\%202feb05.pdf>.

Comissão Interamericana de Direitos Humanos (2009). Caso 12.420, Xákmok Kásek Indigenous Community of the Enxet-Lengua People and Its Members v. Paraguay. Recuperado de: < http:// www.cidh.oas.org/demandas/12.420\%20Xakmok\%20Kasek\%20Paraguay\%203jul09\%20ENG.pdf>. 
Corte Internacional de Justiça. Gabčíkovo-Nagymaros Project (Hungary/Slovakia). Press Release 1998/31. Recuperado de: <http://www.icj-cij.org/en/case/92>.

Corte Internacional de Justiça (2006). Pulp Mills on the River Uruguay (Argentina v. Uruguay). Recuperado de: $<$ http://www.icj-cij.org/en/case/135>.

Hollo, E. J. et al. (2013) Climate change and the law. Nova Iorque: Springer.

Lane, O. (Coord.) (2015). O Direito internacional de águas na América Latina: manual de capacitação. Montevideo: GWP Sudamerica.

Molino, F. B.; Souza, L. C. de. (2015). A política nacional sobre mudança do clima e a responsabilidade comum, porém diferenciada. In: A. C. D. Murta, et al. (Org.). I Encontro de internacionalização do Conpedi Barcelona - Espanha: direito administrativo, direito tributário, direito ambiental, sustentabilidade, 12. Barcelona: Ediciones Laborum, 169-194.

ONU (2018) Relatório Soluções baseadas na Natureza para a Gestão da Água. Programa Mundial das Nações Unidas para Avaliação dos Recurso Hídricos (WWAP). Março. Recuperado de: < http:// unesdoc.unesco.org/images/0026/002615/261579por.pdf >.

ONU (1992a). Agenda 21. Rio de Janeiro, 14 de junho de 1992. Recuperado de: < http://www.mma.gov.br/ responsabilidade-socioambiental/agenda-21/agenda-21-global>.

ONU (1992b). Declaração do Rio sobre Meio Ambiente e Desenvolvimento. Rio de Janeiro, 14 de junho de 1992. Recuperado de: < http://www.onu.org.br/rio20/img/2012/01/rio92.pdf >.

ONU (1972) Declaração das Nações Unidas sobre o Meio Ambiente Humano. Estocolmo, 16 de junho de 1972. Recuperado de: <http://www.direitoshumanos.usp.br/index.php/Meio-Ambiente/declaracao-deestocolmo-sobre-o-ambiente-humano.html>.

Pérez, B. F.(2014). Las migraciones inducidas por el cambio climático en América Latina y el Caribe. In: A. P. Solé, et. al. (Dir). Derecho internacional y comparado del medio ambiente: temas actuales. Barcelona: Huygens Editorial, 333-351.

UNECE (1992) A Convenção sobre a Proteção e a Utilização dos Cursos de Água Transfronteiriços e dos Lagos Internacionais. Helsinque, Recuperado de: <http://www.marinha.pt/Conteudos_Externos/lexmar/ PGPAT\%20100/PGPAT\%201000\%20-\%20Cap\%C3\%ADtulos/Cap\%C3\%ADtulo\%20B\%20Pesca/Subcap\%C3\%ADtulo\%20B.10/B.10.1\%20-\%20Rio\%20Minho/

Decreto22_94_Conven\%C3\%A7\%C3\%A3oAGUA_LAGOS.pdf>. 